\title{
A social work study on socio-economic and cultural factors influencing on community
}

\author{
Mohammad Reza Iravani $^{a^{*}}$, Mostafa Rajabi ${ }^{\mathrm{b}}$, Allahyar Arabmomeni ${ }^{\mathrm{c}}$, Akram Fakhri Fakhramini ${ }^{\mathrm{d}}$ and \\ Mina Shirvani ${ }^{\mathrm{d}}$
}

\begin{abstract}
${ }^{a}$ Assistant Professor, Department of Social Work, Islamic Azad University Khomeinishahr Branch, Daneshjou Blvd, Iran
${ }^{b}$ Assistant Professor, Department of Economic, Islamic Azad University of Khomeinishahr, Islamic Azad University Khomeinishahr Branch, Daneshjou Blvd, Iran

${ }^{c}$ Islamic Azad University of Khomeinishahr, Department of Human Science, Khomeinishahr Branch, Daneshjou Blvd, Iran

${ }^{d}$ MA Student, Department of Sociology, Dehaghan Branch, Islamic Azad University, Isfahan, Iran

\section{A R T I C LEIN F O}

\section{Article history:}

Received January 20, 2013

Received in Revised form

March, 11, 2013

Accepted 7 June 2013

Available online

8 June 2013

Keywords:

Socio-economic

\section{A B S T R A C T}

We present a study to investigate the impacts of four factors on contribution role on society among Arab tribes Jarghoyeh women who live in Iran. The study designs a questionnaire, distributes them among 360 women, and analyzes their feedbacks. There are four hypotheses, which study the effects of various factors on women's contribution role on society. These factors include educational background, level of welfare, numbers of children and ties of kinship. The results show that while educational background, level of welfare and ties of kinship play important role on women's contribution role on society, having more children do not statistically have any influence on juvenile delinquency.
\end{abstract}

Arab tribes Jarghoyeh

Welfare effect

\section{Introduction}

Socio-economic activities play essential role on having better mental health conditions. In fact, low socio-economic status is associated with a higher prevalence of depression (Needham et al., 2001). Lorant et al. (2007) assessed whether longitudinal change in socio-economic factors could influence change of depression level. They reported that a lowering in material standard of living between annual waves was related to increases in depressive symptoms and caseness of some sort of depression. They also stated that life circumstances could also contribute to depression. The study stated it clearly that there was a relationship between worsening socio-economic circumstances and depression. 
According to Butterworth et al. (2012), socio-economic position is associated with depression and the experience of financial hardship, having to go without the necessities of daily living due to limited financial resources, could describe the impact. However, there are few studies investigating the link between financial hardship and diagnosable depression at a population level. Butterworth et al. (2012) tried to address this gap and evaluated the moderating effect of age. They performed an empirical survey and reported on the critical role of financial hardship in the association between socioeconomic disadvantage and 12-month depressive episode. They also suggested that social and economic policies that address inequalities in living standards could be an appropriate way to reduce the burden attributable to depression.

Hudelson (1996) studied gender difference in tuberculosis by investigating the effect of socioeconomic and cultural factors. Rajeswari et al. (1999) performed a survey on socio-economic impact of tuberculosis on patients and family in India. Atre et al. (2004) studied on cultural concepts of tuberculosis and gender among the general population without tuberculosis in rural Maharashtra, India.

According to Sarsani (2011) in all countries, the students of upper socio-economic status (SES) scored substantially higher on creativity than students of upper middle, lower middle, and upper lower socio-economic status. It can be also interpreted that the higher the level of SES, the bigger the chances of being creative. Parental education is associated with family SES and parental education by itself plays an essential role in the development of creativity in their children. Parental occupation and income state inconsistency results. The analysis determines that the effect of SES seems to be more instrumental in fostering or hindering creativity among children.

According to Bucciarelli et al. (2010) investment in education and training plays essential role for socio-economic development, especially in countries where the level of human capital contributes to economic growth. In this context, the complex multi-faceted (ICT) is associated with an important productivity tool as well as to a source of new knowledge. Bucciarelli et al. (2010) investigated the relationship between the variables associated with education and investments, and those referring to ICT field. They provided some support on the usefulness of the dissemination and application of modern technology to education and training processes.

In this paper, we study three factors influencing socio-economical activities among Arab tribes Jarghoyeh women who live in Iran by gathering information from nearly 360 people. The organization of this paper first, presents the questions of our survey in section 2 and the results are given in section 3. Finally, concluding remarks are given in the last to summarize the contribution of the paper.

\section{The proposed study}

The study distributes 360 questionnaires among women from Arab tribes Jarghoyeh. The study investigates the effects of four factors including educational background, welfare level, numbers of children and Ties of kinship on socio-economic activities.

\section{The results}

\subsection{The relationship between educational background and their contribution rate}

The first hypothesis of this survey is associated with the relationship between educational background and contribution rate. Table 1 summarizes details of our survey. 


\section{Table 1}

The relationship between women’s educational background and their contribution role

\begin{tabular}{lcccc}
\hline & \multicolumn{4}{c}{ Contribution role } \\
\cline { 2 - 5 } & & Yes & No & Sum \\
Educational background & Low & 56 & 20 & 76 \\
Sum & High & 153 & 131 & 284 \\
\cline { 2 - 5 } & & 209 & 151 & 360 \\
\hline
\end{tabular}

The Chi-square was calculated as $\chi^{2}=9.663 \mathrm{P}$-value $=0.002$ with $\mathrm{df}=1$, which means we can reject the null hypothesis and conclude that educational background plays an important role on women's contribution role on society.

\subsection{The relationship women's welfare and their contribution role}

The second hypothesis of this survey is associated with the relationship between women's welfare and their contribution role on socio-economic activities. Table 2 summarizes details of our survey.

\section{Table 2}

The relationship between women's welfare and their contribution role

\begin{tabular}{lcccc} 
& \multicolumn{3}{c}{ Contribution role } \\
\cline { 2 - 5 } & & Yes & No & Sum \\
Welfare & High & 52 & 92 & 144 \\
Sum & Low & 122 & 94 & 216 \\
\cline { 2 - 5 } & & 174 & 186 & 360 \\
\hline
\end{tabular}

The Chi-square was calculated as $\chi^{2}=14.357 \mathrm{P}$-value $=0.000$ with $\mathrm{df}=1$, which means we can reject the null hypothesis and conclude that there is a relationship between women's welfare and their contribution role on society.

\subsection{The relationship between women's numbers of children and their contribution role}

The third hypothesis of this survey is associated with the relationship between the relationship between women's numbers of children and their contribution role on society. Table 3 summarizes details of our survey.

\section{Table 3}

The relationship between women's numbers of children and their contribution role on society

\begin{tabular}{lllll}
\hline & \multicolumn{4}{c}{ Contribution role on society } \\
\cline { 2 - 5 } & & Yes & No & Sum \\
Numbers of children & High & 158 & 61 & 219 \\
Sum & Low & 92 & 49 & 141 \\
\cline { 2 - 5 } & & 250 & 110 & 360 \\
\hline
\end{tabular}

The Chi-square was calculated as $\chi^{2}=1.923$ P-value $=0.165$ with $\mathrm{df}=1$, which means we cannot reject the null hypothesis and conclude that there is no relationship between women's numbers of children and their contribution to society.

\subsection{The relationship women's ties of kinship and their contribution role}

The last hypothesis of this survey is associated with the relationship between women's ties of kinship and their contribution role on socio-economic activities. Table 4 summarizes details of our survey. 


\section{Table 4}

The relationship between women's ties of kinship and their contribution role on society

\begin{tabular}{|c|c|c|c|c|}
\hline & \multicolumn{4}{|c|}{ Contribution role } \\
\hline & & Yes & No & Sum \\
\hline & High & 158 & 61 & 219 \\
\hline Ties of kinship & Low & 79 & 122 & 80 \\
\hline Sum & & 105 & 183 & 360 \\
\hline
\end{tabular}

The Chi-square was calculated as $\chi^{2}=14.532 \mathrm{P}$-value $=0.001$ with $\mathrm{df}=1$, which means we can reject the null hypothesis and conclude that there is a relationship between women's ties of kinship and their contribution role on society. In summary, we have found that educational background, welfare well as ties of kinship characteristics play important role on these women to contribute in Iranian society. However, there were no evidences to believe that numbers of children had any impact on their contribution role.

\section{Conclusion}

We have presented a study to investigate the impacts of four factors on women's contribution role on society among Arab tribes Jarghoyeh. The study distributed 360 questionnaires among people who were involved with crime and analyzed their feedbacks. There were three hypotheses in our survey and we were looking to detect whether educational background, welfare level, numbers of children and Ties of kinship play important role on socio-economic activities in Iranian society. The results of our survey indicated that while educational background, welfare well as ties of kinship characteristics play important role on these women to contribute in Iranian society, numbers of children did not statistically influence women's contribution role on society.

\section{References}

Atre, S. R., Kudale, A. M., Morankar, S. N., Rangan, S. G., \& Weiss, M. G. (2004). Cultural concepts of tuberculosis and gender among the general population without tuberculosis in rural Maharashtra, India. Tropical Medicine \& International Health, 9(11), 1228-1238.

Bucciarelli, E., Odoardi, I., \& Muratore, F. (2010). What role for education and training in technology adoption under an advanced socio-economic perspective? Procedia - Social and Behavioral Sciences, 9, 573-578

Butterworth, P., Olesen, S. C., \& Leach, L. S. (2012). The role of hardship in the association between socio-economic position and depression. Australian and New Zealand Journal of Psychiatry, 46(4), 364-373.

Hudelson, P. (1996). Gender difference in tuberculosis: the role of socio-economic and cultural factors. Tubercle and Lung Disease, 77 , 391-400.

Lorant, V., Croux, C., Weich, S., Deliege, D., Mackenbach, J., \& Ansseau, M. (2007). Depression and socio-economic risk factors: 7-year longitudinal population study. The British journal of psychiatry, 190(4), 293-298.

Needham, D. M., Foster, S. D., Tomlinson, G., \& Godfrey-Faussett, P. (2001). Socio-economic, gender and health services factors affecting diagnostic delay for tuberculosis patients in urban Zambia. Tropical Medicine \& International Health, 6(4), 256-259.

Rajeswari, R., Balasubramanian, R., Muniyandi, M., Geetharamani, S., Thresa, X., \& Venkatesan, P. (1999). Socio-economic impact of tuberculosis on patients and family in India. The International Journal of Tuberculosis and Lung Disease, 3(10), 869-877.

Sarsani, M.R. (2011). Socio-Economic Status and Performance on Creativity Tests. Encyclopedia of Creativity, $2^{\text {nd }}$ ed., 360-363 